Research Article

\title{
Design for Manufacturing and Assembly: A BIM-Enabled Generative Framework for Building Panelization Design
}

\author{
Hexu Liu $\left(\mathbb{D},{ }^{1}\right.$ Yuxuan Zhang, ${ }^{2}$ Zhen Lei $\left(\mathbb{D},{ }^{3}\right.$ Hong Xian Li $\left(\mathbb{D},{ }^{4}\right.$ and SangHyeok Han ${ }^{5,6}$ \\ ${ }^{1}$ Department of Civil and Construction Engineering, Western Michigan University, Kalamazoo, MI 49008, USA \\ ${ }^{2}$ Department of Civil and Environmental Engineering, University of Alberta, Edmonton, Alberta, Canada \\ ${ }^{3}$ Offsite Construction Research Centre (OCRC), Department of Civil Engineering, University of New Brunswick, Fredericton, \\ New Brunswick, Canada \\ ${ }^{4}$ School of Architecture and Built Environment, Deakin University, Locked Bag 20001, Geelong, Victoria 3220, Australia \\ ${ }^{5}$ Department of Building, Civil and Environmental Engineering, Concordia University, Montreal, QC, Canada \\ ${ }^{6}$ Centre for Innovation, Construction and Infrastructure Management (CICIEM), \\ Gina Cody School of Engineering and Computer Science, Concordia University, Montreal, QC, Canada \\ Correspondence should be addressed to Hexu Liu; hexu.liu@wmich.edu
}

Received 10 February 2021; Revised 12 April 2021; Accepted 14 April 2021; Published 26 April 2021

Academic Editor: Jia-wen Zhou

Copyright (C) 2021 Hexu Liu et al. This is an open access article distributed under the Creative Commons Attribution License, which permits unrestricted use, distribution, and reproduction in any medium, provided the original work is properly cited.

\begin{abstract}
Offsite construction (OSC) is attracting increasing attention from both industry and academia due to its benefits, such as improved productivity and quality, as well as reduced waste. However, the current building panelization design in OSC is a timeconsuming and experience-based manual process, and the generated panelization design may result in unbalanced manufacturing processes. One reason is that the prefabrication of building components involves a highly variable product mix and there is a lack of a computational framework to evaluate panelization design. The objective of this research is, thus, to propose a BIM-based generative framework that automatically generates the design of production components with the aim of improving production productivity. This framework consists of a building information extraction module, a generative design algorithm, and a simulation-based performance evaluation model. The building information extraction module is designed to extract building component information from a BIM model and classify building components into different production groups in accordance with functionalities and materials. The generative design algorithm is then developed to formulate panelization design alternatives in consideration of the structural, production, and logistics constraints. On this basis, the generated panelization designs are quantitatively assessed by a simulation-based evaluation model in terms of productivity. A case study was used to verify and validate the framework. This research contributes to the body of knowledge by a computational framework of building panelization design, which leverages the generative design algorithm and BIM-simulation integration for optimized panelization design.
\end{abstract}

\section{Introduction}

The construction industry is lagged behind other sectors such as manufacturing in many aspects such as productivity improvement and emerging technology adoption. Industrial practitioners and academic scholars have been seeking all sorts of solutions to improve current practice. For example, Building Information Modelling (BIM) has been applied to facilitate the communication of project stakeholders and decision making across the project life cycle. Despite this, the construction industry did not experience a significant productivity increase. The statistics reveal the average productivity growth of the manufacturing industry is 3.6 times of the productivity growth in the construction industry [1]. In the meanwhile, the construction industry is experiencing a severe labor shortage. It does not attract young generations due to the characteristics of traditional project delivery methods, such as project location changes and low-technology careers. In this context, offsite construction (OSC) is gaining momentum because of its 
potential in addressing these industry challenges. OSC is asserted to significantly enhance operational efficiency and boost construction productivity as building components such as floors, walls, and roofs are manufactured in an environmental-friendly factory with advanced machines. It is envisioned to provide the potentials to further innovate the current construction practice with revolutionized construction processes. As such, plenty of research has been devoted to promoting OSC in the current construction industry.

Despite its perceived benefits, OSC imposes various challenges to construction professionals. For instance, project practitioners need to consider manufacturing constraints in building designs to harness the benefits of manufacturing technology, especially with the advancement of automation and robotic technologies and additive manufacturing. The principles of lean construction and design for manufacture and assembly (DfMA) need to be considered in the design of the OSC project. However, how to effectively panelize buildings under engineering constraints and DfMA principles for manufacturing remains a challenge. Construction practitioners currently need to base their decisions regarding building panelization on their tacit knowledge and rules of thumb. Building panelization herein refers to the plan of dividing the walls of a building into manufacturing panels. For example, some practitioners usually take a specific length as a standardized size in determining wall panels [2]. Others may determine building panelization (e.g., panel length and layout) and panel stacks for minimizing the number of stacks and maximizing stack length $[3,4]$. Consequently, the resulting panelizaition design could take fewer trips when it comes to transportation. Apart from this, truck width has to be considered in the panelization as it is regulated by special transportation permits. Nevertheless, building panel prefabrication involves a highly variable product mix, i.e., a combination of various products with different sizes and features (e.g., opening and connections) [5]. High variations of products cause an unbalanced production line where some workstations are overloaded with other stations being idle. Wall panels may have a longer waiting time before they can be processed with the required operations in the following workstations. Eventually, it could take a longer duration for an unbalanced production line to produce the wall panels of the building, resulting in low productivity. In such a case, current building panelization practice cannot achieve the anticipated benefits of OSC, such as improved productivity and reduced waste.

In addition, the existing literature neglects the construction performance (e.g., productivity) attributed to different building panelizations. There is a lack of a computational framework for building panelization. Decisionsupporting tools are not available to practitioners to perform building panelization designs for OSC projects. To this end, this research explores an automated BIM-based generative approach to building panelization with a focus on the wall system of light-frame buildings. This research contributes to the body of knowledge by a BIM-based generative framework. Such a framework can incorporate both a rule-based wall panelization generative algorithm and the quantitative construction performance evaluation based on the integration between BIM and construction simulation. As such, the framework can preserve trade know-how in the automated development of wall panelization design while improving production productivity based on quantitative productivity measures.

The remainder of this paper is organized as follows. In Section 2, previous research regarding design for manufacturing and assembly, design optimization, and selection of the OSC system is reviewed to clarify the research gap. Subsequently, the proposed methodology is illustrated in Section 3 in detail. Sections 4, 5 and 6 presents the prototype development and case study, as well as their results. The final section concludes the paper, highlighting the research contribution.

\section{Literature Review}

As described earlier, OSC can remarkably innovate the construction industry into more sustainable practice with revolutionized construction processes. Research efforts have been increasingly directed toward OSC from both design and construction perspectives, such as design for manufacturing and assembly, design optimization for prefabricated buildings, and lean construction. This section presents a comprehensive review of these aspects.

2.1. Design for Manufacturing and Assembly. Project designers need to consider criteria in both conventional product design and manufacture, logistics, and assembly processes when designing OSC projects [6]. As such, different design criteria, procedures, and guidelines in the OSC have been developed in the industry, namely, design for manufacturing (DFM), design for assembly (DFA), design for logistics (DFL), and DFMA [7]. Among them, DFMA intends to integrate different professional knowledge into the design stage so as to improve the manufacturability and assembly performance of prefabricated building elements [8]. For instance, Alfieri et al. [9] proposed a BIM and DfMA-based design workflow for building construction. Their workflow can improve the current design process by identifying the information requirements of downstream activities during the early design stage. Gao et al. [10] explored the factors that impact the DfMA adoptions in the context of Singapore. The identified factors include construction time reduction, increased quality, transportation and erection challenges, use of BIM, and so forth.

In fact, new technologies such as BIM have been proposed for the uses for OSC projects, such as design and construction management. In particular, how to integrate DFMA with BIM has been increasingly studied in recent years. For instance, a novel design process was developed to incorporate the parametric design of BIM with DFMA for prefabricated buildings [11]. DFMA principles are used to evaluate precast component designs in the DFMA-oriented parametric design processes. Similarly, Sharma et al. [7] explored a BIM-based framework to increase the design 
coordination and mitigate the rigidity of the OSC design process in consideration of DFM and DFL. Staub-French et al. [12] investigated the synergies between BIM and DfMA in mass timber construction. More recently, Alwisy et al. [13] developed an automated BIM approach for designing and drafting modular buildings in consideration of manufacturing requirements. All these efforts were to qualitatively consider DfMA design principles but fail to quantitatively factor construction performance in the design.

Similarly, DFM and DFA concepts are described as product-based design and project-based design. In this respect, Ramaji and Memari [14] investigated a product architecture model in consideration of the product-based nature of manufactured building elements and the projectbased nature of on-site assembling. Their proposed model extended the BIM platform to facilitate OSC and provided an information management framework. Chen and Lu [15] applied the DFMA principles to the design of a practical curtain wall system using BIM and concluded that these principles could achieve increased quality, sustainability, and cost efficiency associated with the assembly process. These efforts were primarily undertaken to look at how the DFX (i.e., DFA, DFM, and DFMA) principles, processes, and philosophy from the manufacturing industry can be applied to building design during the early design stage.

2.2. OSC Design Optimization. Besides, there have been many efforts attempting to optimize the modular design of OSC projects in the project life cycle. For instance, prefabrication strategies (e.g., modularization) were integrated into the early design configuration process for the design automation of OSC projects [16]. A unified matrix method was introduced to automate the spatial design of multistory modular buildings during the early design stage [17]. To achieve the near-optimum selection of module configuration for precast buildings, Salama et al. [18] proposed a unified modular suitability indicator. The modular suitability indicator is the weighted sum of five indices, including (1) transportation distance to construction job sites, (2) transportation dimensions, (3) connections of modules on site, (4) crane operating condition and related cost, and (5) project concrete foundation.

On the contrary, Isaac et al. [19] develop a graph-based methodology to decompose the building design into nonrepetitive modules based on BIM. These separated modules can be readily replaced for renovation and adapting buildings for other needs. Banihashemi et al. $[20,21]$ developed a generative algorithm based on modular coordination rules and proposed a workflow of integrating parametric design (i.e., generative mechanism, design constraint, and rule-based design) into modular coordination so as to reduce construction waste. Gbadamosi et al. [22] developed a BIM-based design optimization system, which assists designers in selecting building elements and materials for building envelope during the early design stage. Four metrics, including (1) ease of assembling; (2) ease of handling; (3) speed of assembling; and (4) assembly waste, are included in the design assessment, and AHP is applied to determine their weights of the design assessment model. In addition to these efforts into the early design of OSC projects, Said et al. [23] developed an exterior panelized wall platform optimization (EPWPO) model to tackle the tradeoff between production efficient and design flexibility, i.e., maximize the commonality between the wall panels while maintaining the design variety. Total fabrication cost and design deviation index were developed as two new factors in evaluating panel platform design.

2.3. Selection of the OSC System. OSC can be carried out at various levels of prefabrication degrees, such as panelized construction, modular construction, and hybrid construction. Panelized construction is the most common OSC method where individual building elements are prefabricated. On the contrary, modular construction represents a higher level of prefabrication where building elements are manufactured into modules. Configuring a higher level of prefabrication can reduce production, transportation, and installation cost [2]. However, $\mathrm{Lu}$ et al. [24] reported that a higher degree of prefabrication does not guarantee a better construction solution. Modular construction is marginally more cost effective for single-family homes than panelized construction [25]. Given this, several decision support systems and models were developed to assist project stakeholders in selecting offsite construction methods. For instance, a construction method selection model was developed by Chen et al. [26] based on multiattribute utility theory for choosing the prefabrication degree for concrete buildings, i.e., the entire building or parts of a building.

Recently, a Delphi-method-based analytical framework was proposed to determine the optimal level of building prefabrication. Thirteen factors, including political factors, economic factors, social factors, and technological factors, have been identified and summed to score five prefabrication levels. Such a proposed framework, it should be noted, is intended to assist in selecting the optimal prefabrication level for countries or regions rather than individual building projects. Another interdisciplinary decision-making framework for selecting a prefabricated constructional system for roof stacking was developed by investigating 136 case projects and semistructured interviews [27]. Various factors, such as safety, logistics, cost, time, environmental impact, and construction quality, were considered in this framework. Besides, the analytical hierarchy process (AHP) technique was successfully applied in identifying the optimal OSC systems among nonvolumetric systems, volumetric systems, and hybrid systems [28]. Nevertheless, these frameworks and models cannot answer the questions of how to break buildings into modules and components and how different building panelization alternatives affect construction performances.

\section{Methodology}

Optimizing building panelization has implications for enhancing project outcomes such as the highest productivity. 
As such, this research aims at a BIM-based generative framework for building panelization design with a particular focus on light-framed walls. Figure 1 shows the proposed framework that assists construction practitioners in securing the optimized panelization design. At first, rich information of building elements is retrieved from a given BIM model and fed as input for subsequent design generation and analysis. Tacit knowledge with respect to panelization in the light-frame building industry is formalized as design rules. On this basis, a panelization design algorithm is developed so as to generate a variety of panelization designs satisfying the constructability requirements such as structural integrity and transportation capacity. The constructability constraints are considered to assess the feasibility of the panelization design across various construction phases. Afterward, an evaluation model is developed to evaluate the construction performance of the panelization designs. All generated feasible alternatives are evaluated for their performance in terms of manufacturing productivity. Discrete event simulation (DES) is employed to assess the manufacturing productivity, leveraging its capability of mincing the production processes. Ultimately, a panelization design with optimized productivity is identified as the final design. In the following sections, each step in the proposed methodology is described in detail.

3.1. Building Information Extraction. BIM is an information-rich database and provides rich building information for the panelization design analysis. In specific, BIM herein refers to the digital building model, where building elements are defined with specific size and shape. The construction details, such as precise stud layout, it should be noted, are missing from the BIM. It is because such BIM is primarily developed by the architect and engineer rather than construction professionals. As such, BIM offers wall layout and other wall information such as function, dimension, layers, and the like for wall panelization design analysis.

The information model of the panelization design for light-frame wood buildings is identified in the presented research. Figure 2 illustrates the excerpt of the identified information model. As shown in Figure 2, "BuildingComponent" is the base class that carries all general information about building components. "Wall" is inherited from "BuildingComponent" and extended with specific properties and functions such as "IsExterior," "Doors," and "Connections" indicating their topological relationship among wall elements. "WallLayer" is inherited from "Geometry" and carries all geometric information of each wall layer. It is associated with "Wall" as walls usually consist of multiple layers such as drywall, insulation, and framing layers. These classes are defined by the authors within Visual Studio and used to hold building information. The Autodesk Revit Application Programming Interface (API) was used to develop a BIM parser and retrieve such information from a given BIM model.
3.2. Generative Panelization Design. Building panelization is to break down the building product into $2 \mathrm{D}$ panels for production. There are certain principles and constraints in building panelization, such as (1) structural integrity, (2) industrialized construction processes, (3) construction machinery and robotic, (4) transportation logistics, and (5) lifting capacity. Among these, transportation capacity, lifting capacity, and structural integrity are constructability constraints. These constraints have to be satisfied for all components to be transported and assembled into the final production. On the contrary, the remaining constraints, such as industrialized construction processes, are related to construction performance (i.e., performance constraints). For example, the panelization of building panels needs to maximize the benefits of industrialized construction processes in less waste and higher productivity. Ideally, the building panelization design should allow for a balanced production line, efficient manufacturing, and easy assembly.

This research formalized the building panelization design rules related to constructability constraints for lightframe buildings. Typically, these rules include (1) the size limit of wall panels (i.e., maximum and minimum length) and (2) opening avoidance (see Figure 3). The size limit of wall panels is primarily sourced from the manufacturing capability of equipment in the wall production line and the size of transportation trailers. The opening avoidance is in consideration of structural integrity as the connections at openings could cause cracks for walls. These rules are considered in the panelization design analysis and encoded in the design algorithm to ensure the constructibility of the generated panelization alternatives.

Figure 4 presents the flowchart of the wall panelization design algorithm. To begin with, the algorithm obtains the stud and plate layout as per design specification. For example, the studs are placed at the spacing of 16 inches on the center, which are commonly used for load-bearing walls. Afterward, an iteration process is triggered to formulate feasible design alternatives. One iteration generates one panelization design alternative. For each iteration, the algorithm first randomly selects one target panel length so that the number of panels (i.e., N) for each wall can be further calculated; then, the number of "N-1" vertical studs is randomly selected as dividing points to break walls into wall panels. It should be noted that vertical studs herein exclude king stud, jack stud, and cripples around openings because of opening avoidance requirements. Leveraging enrich information from the BIM model, all studs in walls carry an attribute of lumber functions.

The examples are king, jack, cripples, vertical, end, and joint. As such, these studs are distinguishable so that vertical and joint studs can be readily filtered for design generation. By doing this, the rule of opening avoidance can be satisfied. Following this, the lengths of all generated panels are calculated based on dividing points and checked against the maximum and minimum panel length to ensure all panels satisfy the size limit. If not satisfied, the algorithm reselects the dividing points for new panelization until this rule is satisfied. Finally, the stud layout is adjusted to make wall 


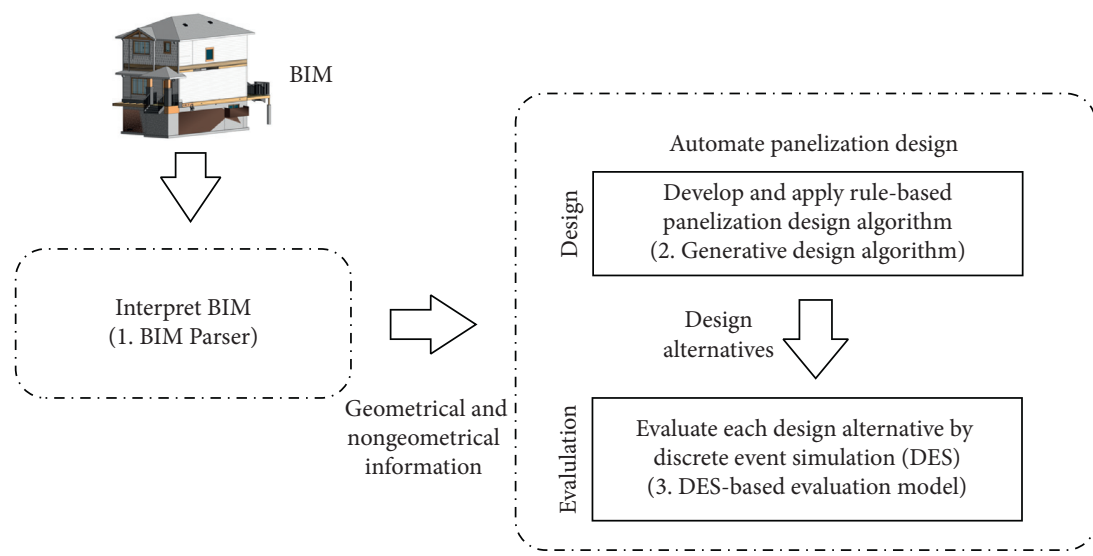

Figure 1: Research methodology.

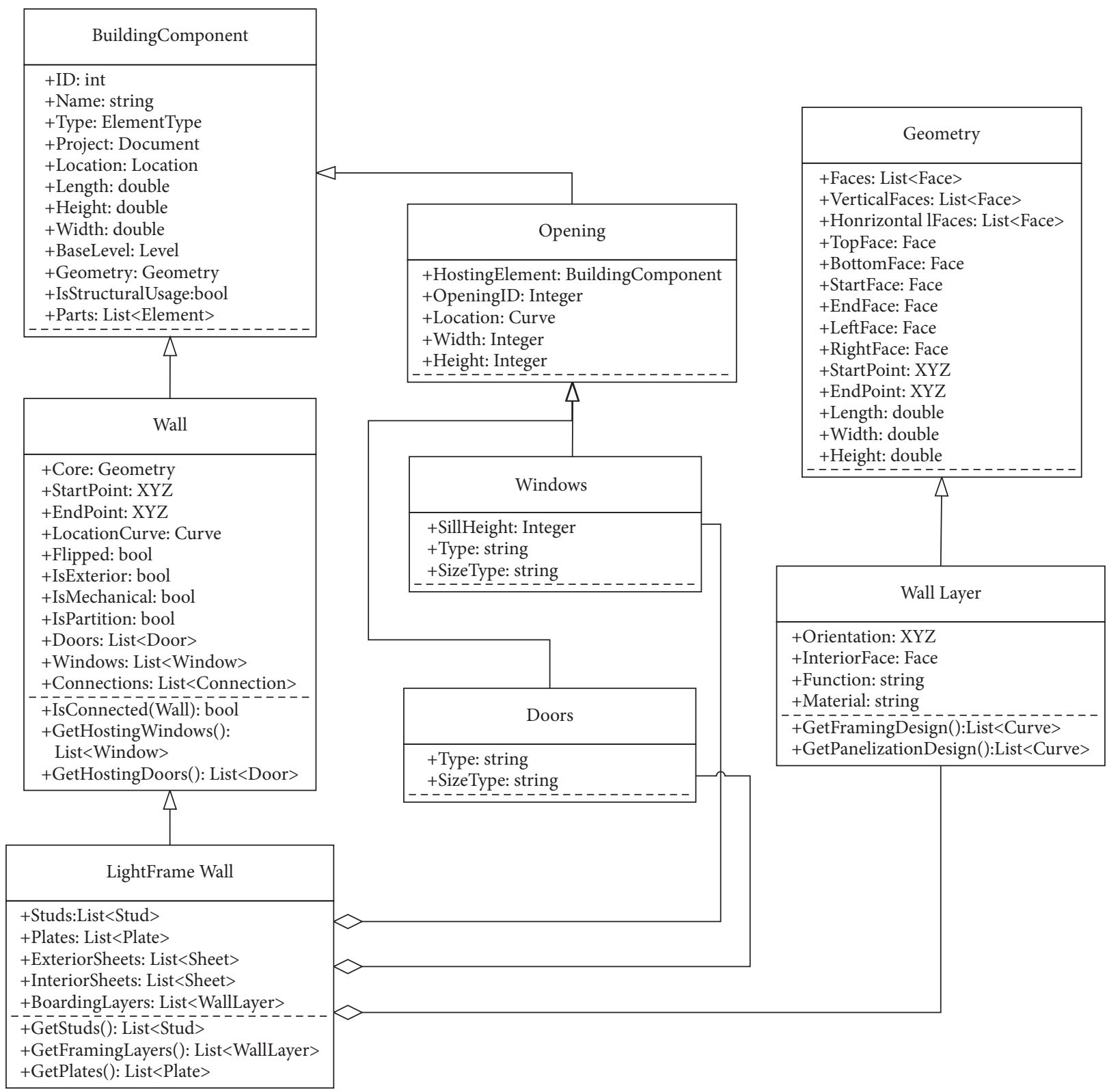

FIgURE 2: Building information for panelization design. 


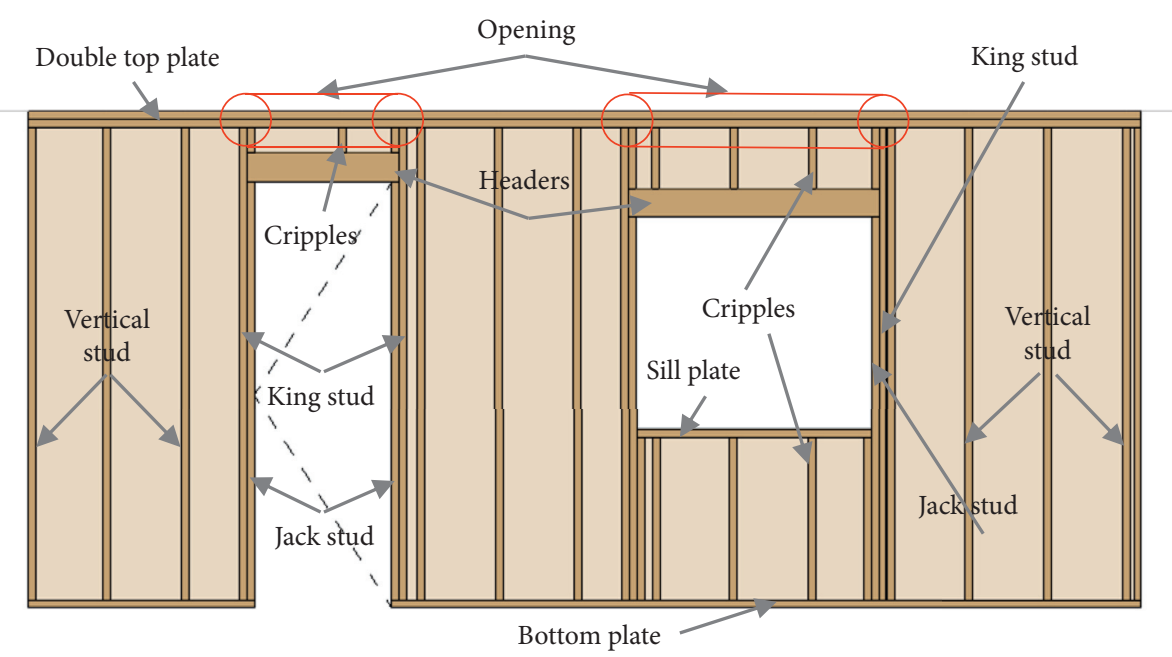

Figure 3: Wall frames with openings.

panels. That is, a new vertical stud is added at the dividing points for wall panels. The iterative processes do not stop until all walls have been panelized. The design algorithm does not terminate until a specific iteration has been reached. By the end of the iteration process, a specific number of feasible panelization designs can be generated by the proposed algorithm. The construction performance for each of the generated designs is then determined using the simulation-based evaluation model described in the following section.

3.3. Simulation-Based Performance Evaluation Model. The optimized panelization design is determined based on evaluating their performance with regard to manufacturing productivity. This research employs discrete event simulation to simulate manufacturing processes for productivity prediction and evaluation. The development of the simulation-based performance evaluation model is described in this section.

3.3.1. Wall Panel Production Process. The panelized wall panels are manufactured in a wall production line equipped with advanced machines for automation. This section describes the wall production processes. Generally, the wall production line consists of several workstations where specific operations are carried out to produce the aforementioned 2D building components. Table 1 presents workstations, operations within each workstation, activity duration, and station capacity. These data are collected from one wall production facility of the industrial partner.

In general, the fabrication process begins with wood studs and plates being placed together into panel frames. Nailing is then carried out by a computer numerical control (CNC) machine in order to form the panel into a rigid frame. These two operations are performed in the workstation of "Framing Table." Subsequently, framed wall panels are transferred to the sheathing station and multifunction bridge, where sheathing sheets are placed and nailed with the support of advanced equipment (i.e., multibridge).
Following this, the wall panels go through the tilting and butterfly table sequentially for wall panels to be flipped over. After that, only exterior wall panels are then sent to "Spray Booth" for insulation. Wall panels without windows and doors are sent to the wall magazine line. Wall panels requiring windows and doors are transferred to the window and door installation station before they are moved to the storage area.

3.3.2. Process Simulation Modelling. To predict the production performance, a simulation model was developed, which mimics the production line described above. Simphony NET 4.6 [29] is employed to create the simulation model. It is selected because of (1) its capability for users to write codes for advanced simulation modeling, (2) simulation entities, (3) the ability of simulation entities to carry attributes, (4) an opensource simulation engine library, and (5) its special-purpose template. Simulation entity and its ability in carrying attributes are the keys for the BIM-DES integration in this research, which is described in Section 4. The research presented in this paper employs the previously developed special-purpose template for simulation model development. It should be noted that the special-purpose simulation template is a customized simulation environment for building production management [30]. It can expedite the simulation model development by providing customized and easy-to-use simulation elements. Consequently, the end-users can readily use customized elements (e.g., Station Element), link them together, and provide input parameters (e.g., capacity of physical station) to develop the simulation model of a wall production line. The readers can refer to the authors' previous publications, such as that of Liu et al. [30], for details regarding the simulation tool.

In general, one workstation in the physical production line is represented by one station element of the simulation tool. The 'Station' simulation element has several input parameters such as Capacity and Unit. These parameters allow users to define capacity and capacity units to regulate the simulation entities and mimic the production flow. For example, the framing table in the production line is 40 feet 


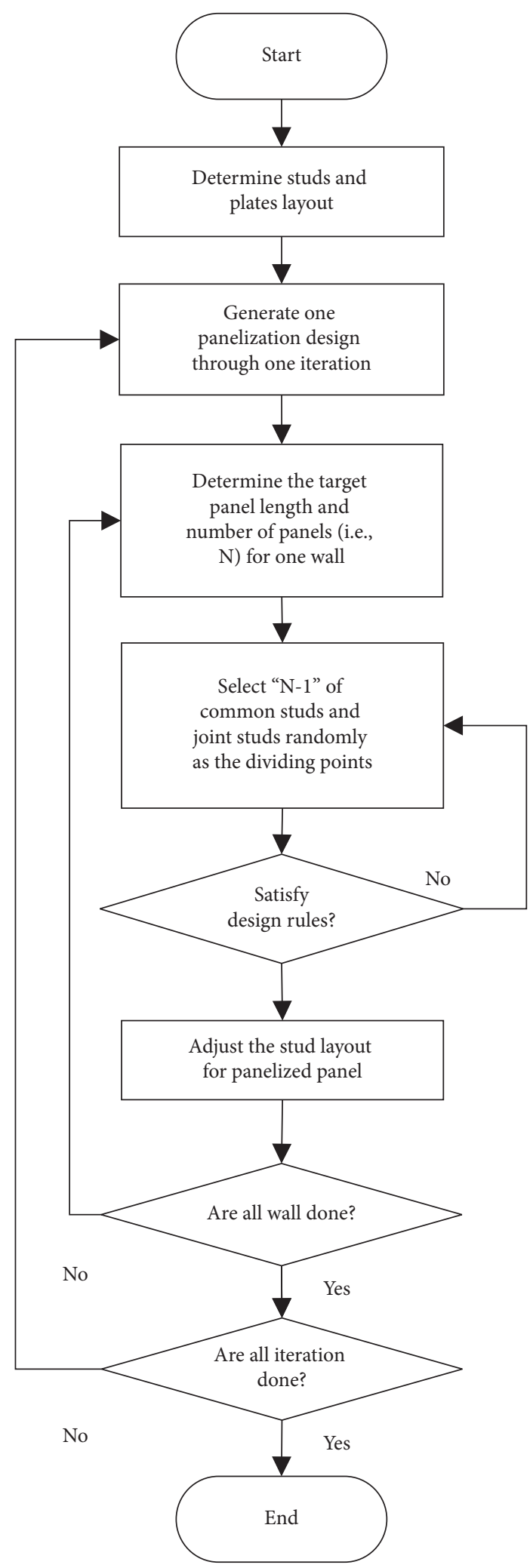

FIGURE 4: Wall panelization design algorithm.

long. As such, it provides 40-feet-long space for wall panels. When a simulation entity (representing a wall panel) enters the framing table in the simulation model, the panel length is checked to ensure that sufficient space is available for the panel. If the room is insufficient, the wall panel is waiting for the new space to open; otherwise, the wall panel entity can be immediately moved to the framing table for framing activities. In addition, construction operations are carried out for a specific duration with the support of construction resources such as labor and equipment. In this aspect, the station element allows users to specify resource requirements and duration for each operation. For example, the framing station requires two labors (i.e., one assembler and one framer) in carrying out the framing activities, such as prepare for a new panel, load the top and bottom plate, framing studs, and label panels and move it out. These labor resources and activities are defined and placed within the "Framing Station," as shown in Figure 5. Activity durations in workstations are collected in the manufacturing field and are fitted into probability distributions and linear models as tabulated in Table 1. For example, the duration for the activity of "Framing studs" is expressed as follows:

$$
\begin{aligned}
\text { Duration Framing studs }= & 83+(N c+N j+N k+N v \\
& \times 10+77.28 \times N L D+N W) \\
& +45 \times \mathrm{NRD}+\mathrm{NSD}+40.16 / 60,
\end{aligned}
$$

where Nc denotes the number of cripple studs in a wall panel, $\mathrm{Nj}$ is the number of jack studs, $\mathrm{Nk}$ denotes the number of kings, Nv represents the number of other vertical studs, and NLD, NW, NRD, and NSD denote the number of larger doors, windows, regular doors, and small doors, respectively.

It should be noted that operations within each workstation, activity duration, and station capacity are collected from one wall production facility of the industrial partner. The reliability of the simulation inputs was described in the authors' previous research. The research presented in this paper primarily focuses on the generative panelization design algorithm and BIM-DES integration for construction performance evaluation. For a detailed time study of the production line under study, the readers could refer to the previous publication, such as the work of Sadiq et al. [23].

Upon completing the simulation run, the simulation elements in the employed simulation tool also collect the statistics data; for example, the station element collects cycle time, utilization, and waiting time for work stations. These statistics provide data-driven insight for practitioners to base the decision making and balance the production. Figure 5 presents the simulation model network, consisting of station elements for each physical workstation in the production line. It mimics the production process described earlier and can predict the production time to indicate the optimality of the panelization design with respect to productivity.

\section{Prototype Development}

To implement the proposed method, a panelization design tool is developed as an add-on to the Autodesk Revit platform using its API. Figure 6 illustrates the system architecture for the developed tool. As shown in the figure, it consists of three modules, namely, (1) a BIM parser; (2) a 
TABle 1: Station, activities, and their duration for wall panels.

\begin{tabular}{|c|c|c|}
\hline Station (capacity) & Task & Duration \\
\hline \multirow{4}{*}{$\begin{array}{l}\text { Framing station ( } 40 \\
\text { feet long) }\end{array}$} & Preparation & Triangular $(1.77,2.77,1.89)$ \\
\hline & $\begin{array}{l}\text { Load top and } \\
\text { bottom plates }\end{array}$ & $(60+($ NumBottomPlates + NumTopPlates $) / 2.0 \times 10+\operatorname{triangular}(0.2,3.0,1.5)) / 60$ \\
\hline & Framing studs & $\begin{array}{c}(83+(\text { NumCripples }+ \text { NumJStuds }+ \text { NumKStuds }+ \text { NumVStuds }) \times 10+77.28 \times \\
(\text { LargeDoor }+ \text { NumberofWindow })+45 \times(\text { RegularDoor }+ \text { SmallDoor })+5.48 \times 2+7.10 \times 2+15) / \\
60\end{array}$ \\
\hline & $\begin{array}{l}\text { Label panel and } \\
\text { move it out }\end{array}$ & $0.21+$ triangular $(0.0,0.1,0.05)$ \\
\hline \multirow{5}{*}{$\begin{array}{l}\text { Sheathing station ( } 40 \\
\text { feet long) }\end{array}$} & $\begin{array}{l}\text { Move in, label } \\
\text { panel }\end{array}$ & $0.5+\left(0.85^{*} 1\right)$ \\
\hline & Place hooks & $0.5 \times 2$ \\
\hline & Move panel & 0.5 \\
\hline & Error correction & 2 \\
\hline & Place OSB & Area $/ 32.0 \times 2.02+$ triangular $(3.0,3.1,3.05)$ \\
\hline \multirow{6}{*}{$\begin{array}{l}\text { Multifunction bridge } \\
\text { ( } 40 \text { feet long) }\end{array}$} & Receive panel & 0.5 \\
\hline & Input computer & 0.5 \\
\hline & Nail refill & $2(4 \%$ chance for refill $)$ \\
\hline & & Placement $=0.55+\operatorname{area} / 32.0^{*} 0.30$ \\
\hline & Nailing OSB & Delay $=$ triangular $(0.5,8.33,0.833)$ \\
\hline & & Total $=$ placement + delay + triangular $(1.0,1.1,1.05)$ \\
\hline \multirow{2}{*}{ Tilting table (1) } & $\begin{array}{l}\text { Move to the tilting } \\
\text { table }\end{array}$ & 0.5 \\
\hline & $\begin{array}{l}\text { Move to the } \\
\text { butterfly table }\end{array}$ & 1.2 \\
\hline Butterfly table (1) & Transfer panels & $\begin{aligned} \text { Unload } & =0.35 ; \text { receive }=0.4 \\
\text { Total } & =\text { unload }+ \text { receive }\end{aligned}$ \\
\hline Spray booth (3) & $\begin{array}{l}\text { Spraying }(1 \\
\text { sprayer })\end{array}$ & $\begin{array}{c}\text { if }(\text { SprayArea }<4) \\
\text { Duration }=2 \times 0.5 \\
\text { Else } \\
\text { Duration }=0.5 \times(19.43+0.4895 \times \text { SprayArea })\end{array}$ \\
\hline Bypass line (1) & Transfer window & 2 \\
\hline \multirow{9}{*}{$\begin{array}{l}\text { Window-door } \\
\text { installation (1) }\end{array}$} & Wrap plastic & $\begin{array}{c}\text { attach } 1=2 \times(\text { NumberofWindow })+0.67 \times(\text { Rdoor }+ \text { Ldoor }) ; \\
\text { attach } 2=(1.25+1.5) \times(\text { NumberofWindow }+ \text { Rdoor }+ \text { Ldoor }) ; \\
\text { Total }=\text { attach } 1+\text { attach } 2 ;\end{array}$ \\
\hline & Adjust panel & 0.5 \\
\hline & Place small OSB & NumberofWindow + Ldoor + Rdoor; \\
\hline & $\begin{array}{l}\text { Bring and place } \\
\text { windows and door }\end{array}$ & $3 \times$ Lwindow $+2 \times$ Rwindow $+2 \times$ Swindow $+3 \times$ Ldoor $+2 \times$ Rdoor $+2 \times$ Sdoor \\
\hline & Attach to wall & $5.5 \times$ Lwindow $+3.5 \times$ Rwindow $+2.5 \times$ Swindow $+12 \times$ Rdoor + Ldoor \\
\hline & Spray foam & $2.75 \times($ NumberofWindow + Rdoor + Ldoor $)$ \\
\hline & Glue and staple & $5 \times($ NumberofWindow + Rdoor + Ldoor $)$ \\
\hline & Tape & $1 \times($ NumberofWindow + Rdoor + Ldoor $)$ \\
\hline & Install protection & $1 \times($ NumberofWindow + Rdoor + Ldoor $)+0.5$ \\
\hline Transfer cart (1) & $\begin{array}{l}\text { Load, travel, } \\
\text { unload }\end{array}$ & $\begin{array}{l}\text { //travel to destination:load, travel, unload panel } \\
\text { Dur }=0.5+0.7+1+0.5\end{array}$ \\
\hline Magazine line (50) & $\begin{array}{c}\text { Wall panel storage } \\
\text { area }\end{array}$ & No activities \\
\hline
\end{tabular}

panelization design generator; and (3) a simulation-based evaluation model. The panelization design generator can take rich information from a BIM model in the form of object-oriented building components and formulate various feasible panelization design alternatives. Once the panelization designs are developed, wall panels and their data are fed into the DES-based simulation model via object-oriented entities. It should be noted that Simphony provides a concept called "entities," which carry attributes with them as they move through the process simulation model network [29]. In this sense, building components with their attributes (see Figure 2) are fed into the Simphony-based DES model as entities in this research. The DES-based evaluation model, in turn, mimics the manufacturing processes to predict the production time for each panelization design and provide statistics on the production performance. The three modules' integration is achieved by object-oriented building components (see Figures 2 and 6). 


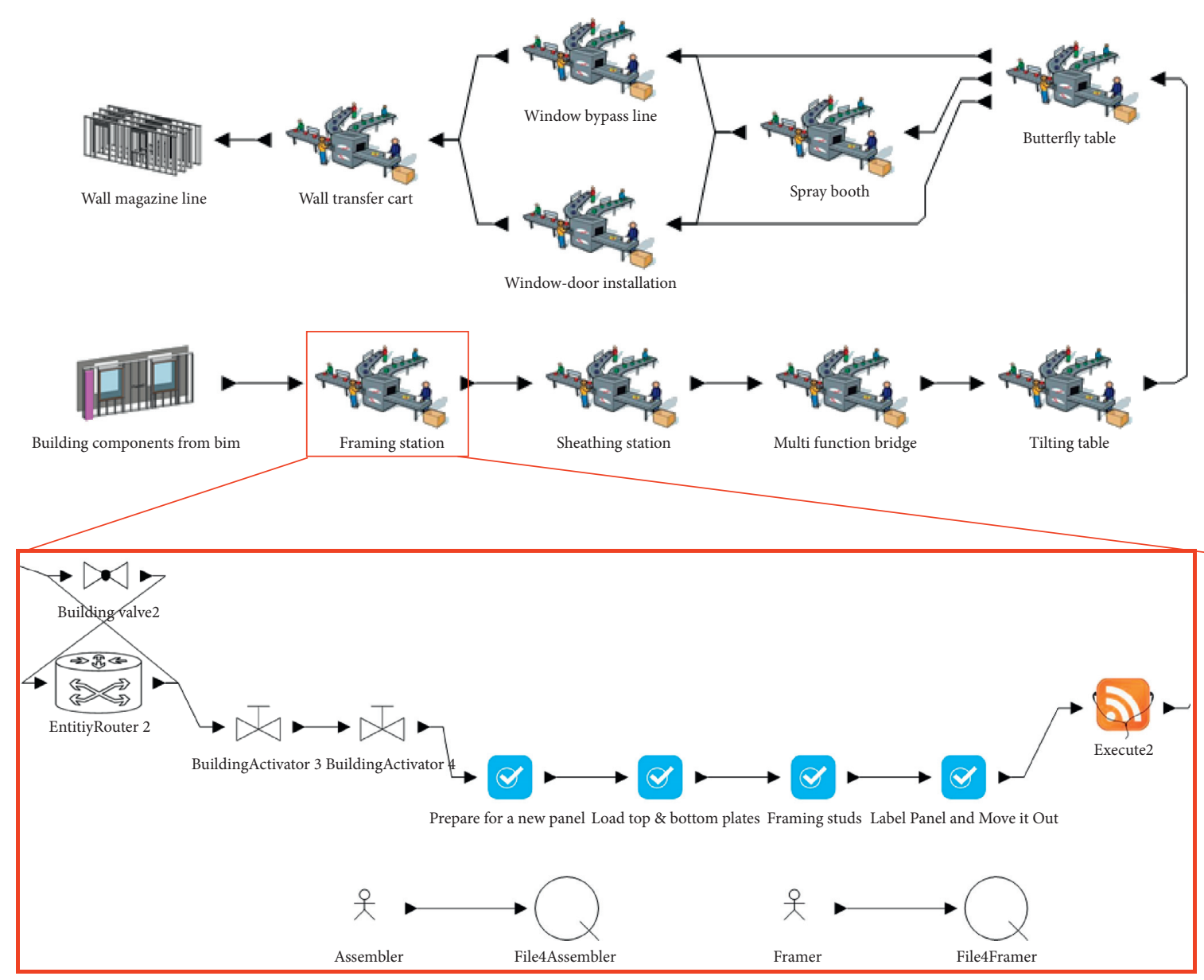

FIgURE 5: A simulation model of the wall production line.

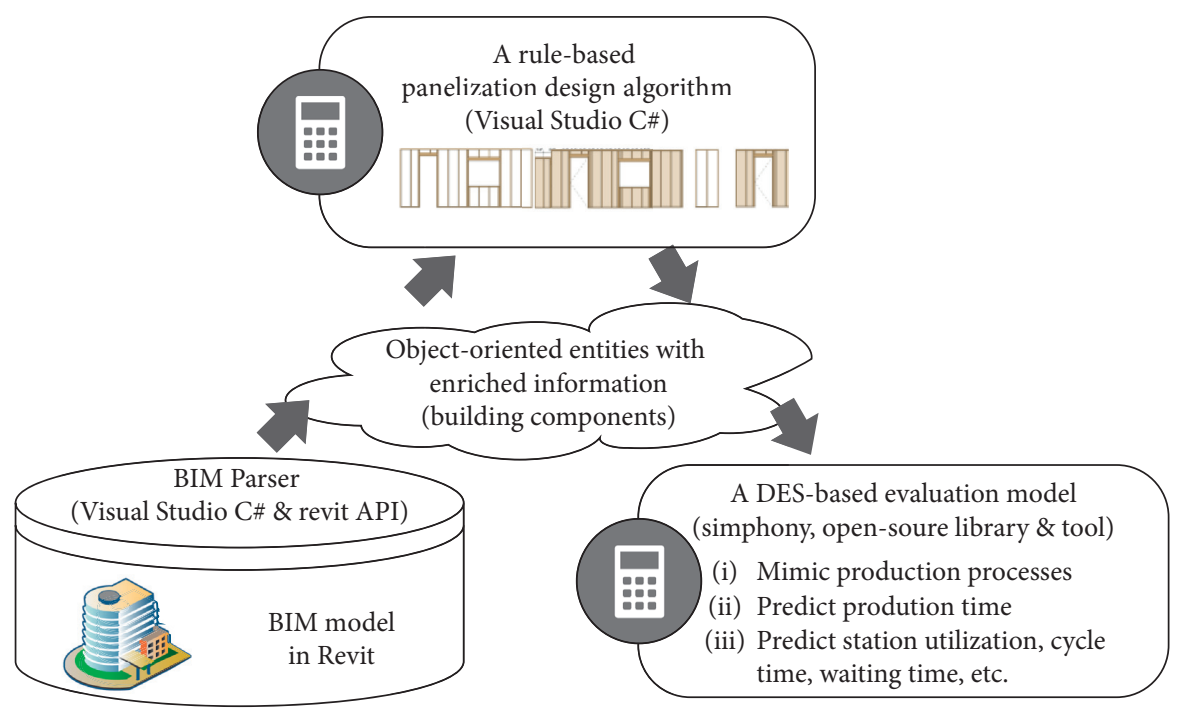

FIgURE 6: System architecture.

It is worth noting that Simphony is not only a simulation environment with a graphic user interface but also an open-source simulation engine library. Capitalizing this critical feature, the simulation model (see Figure 5) is developed through the graphical user interface by using the graphic simulation construct of Simphony. The developed Simphony model can be called and run through a C\# program. As such, the developed simulation model of the 


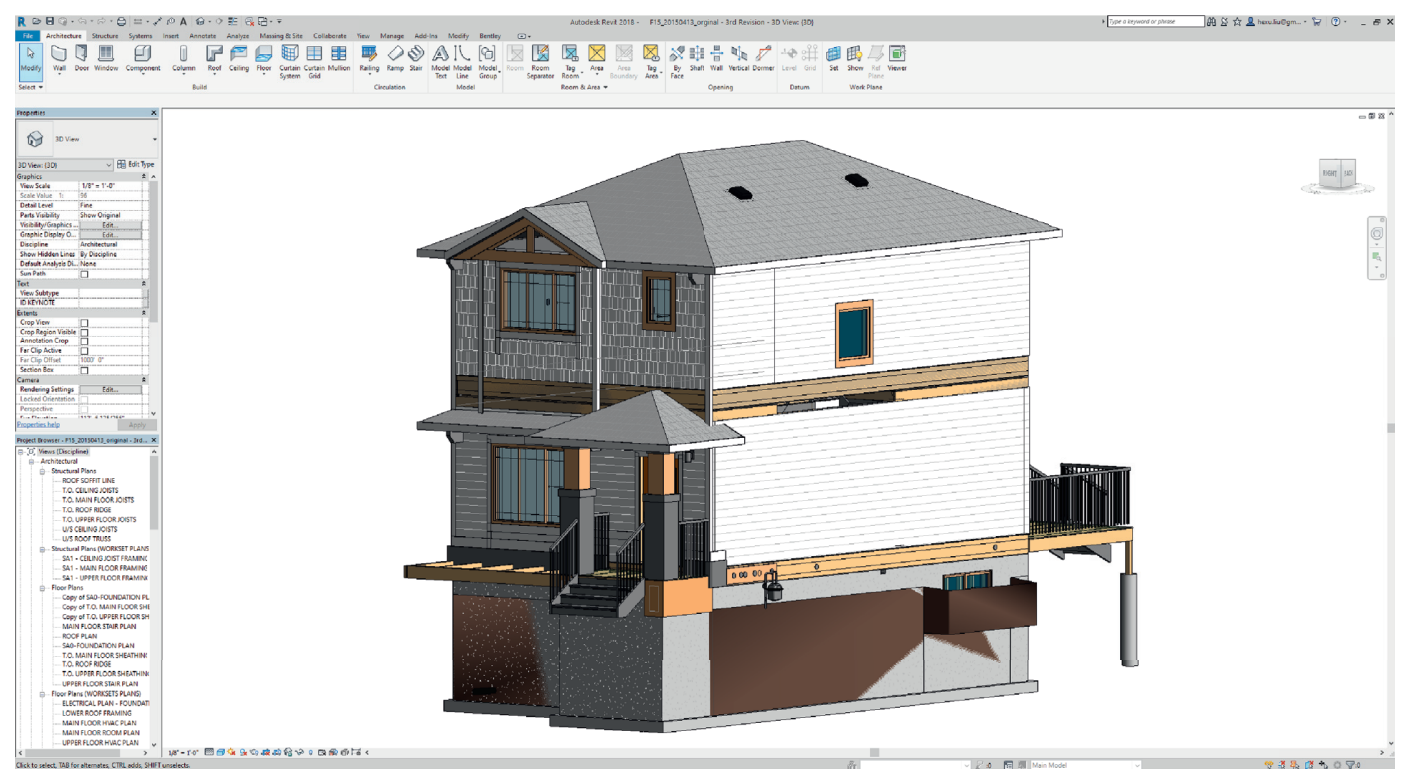

Figure 7: A residential home case study: 3D view.

wall production line is run within the developed Revit addon. All three modules are, thus, encoded together as a developed Revit add-on.

\section{Case Study}

A single-family house is selected as a case study to test the developed prototype system. Figure 7 shows the BIM model of the chosen case, which was built in Autodesk Revit 2018. The superstructure of this residential home consists of two stories and 53 light-framed walls, including 12 exterior walls and 41 interior walls. The building also contains various typical features such as windows and doors and serves as a representative example to verify and validate the developed system. The lengths of exterior walls average at 17.4 feet, with a maximum length of 32 feet. The developed prototype is used to panelize the exterior light-framed walls in this house. It should be noted that the selected building case is a real building produced by the industrial partners. Its BIM model was thoroughly checked by the partner and used to create various design drawings and documentation for production. The output of the prototyped system is the panelization design in the form of textual information. That is, the BIM model in this research provided inputs for the developed system, while the final panelization design by the developed system needs to be incorporated into the 3D BIM model manually. In turn, the manual modeling of the generated panelization design helps verify and validate the panelization design algorithm.

\section{Results}

A. The prototyped system can automatically generate panelization design for the case study, eliminating the manual efforts of construction practitioners in
TABLE 2: Wall panelization results.

\begin{tabular}{lc}
\hline Wall ID & Number of panels \\
\hline M1 & 2 \\
M2 & 3 \\
M3 & 2 \\
M4 & 3 \\
U1 & 3 \\
U2 & 2 \\
U3 & 3 \\
U4 & 1 \\
U5 & 1 \\
U6 & 1 \\
U7 & 1 \\
U8 & 1 \\
\hline
\end{tabular}

panelization design. The system outputs are the panelization design in the form of textual information and are saved into an XML file. Table 2 tabulates the panelization design for exterior walls. For example, the wall, M1, is broken down into two wall panels. In the interest of brevity, Figure 8 shows the resulting design for the wall, i.e., M1. The results are thoroughly checked in regards to design constructability. The generated layout complies with practical know-how, such as opening avoidance, implying the rule-based design algorithms can formulate the feasible design alternative based on rich information extracted from the given BIM.

6.1. Productivity. Apart from the constructability, the productivities are checked to confirm that the prototyped system can generate the panelization design with shorter production duration. The production duration of generated panels is compared with the one without panelization to validate the proposed system. Table 3 summarizes the production durations of the panelization design generated 


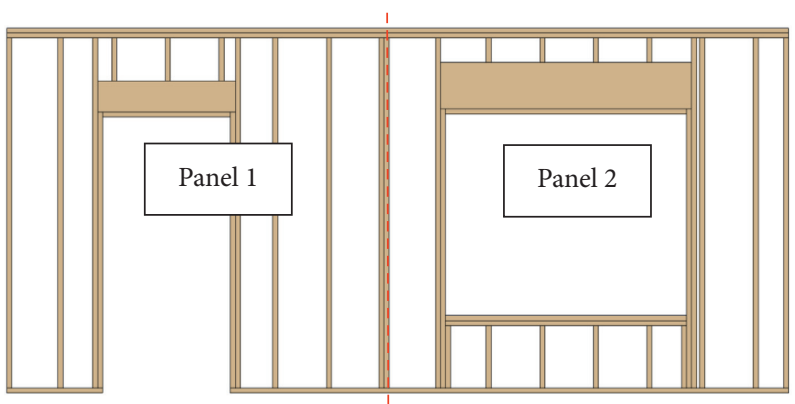

Figure 8: Panelized wall frames.

TABle 3: Panelization designs and their production duration.

\begin{tabular}{lccc}
\hline Panelization alternative & Number of panels & Average production time (min) & Time saving \\
\hline$\# 1$ & 20 & 290.08 & $9.6 \%$ \\
$\# 2$ & 27 & 307.82 & $5 \%$ \\
$\# 3$ (original walls) & 12 & 321.16 & - \\
\hline
\end{tabular}

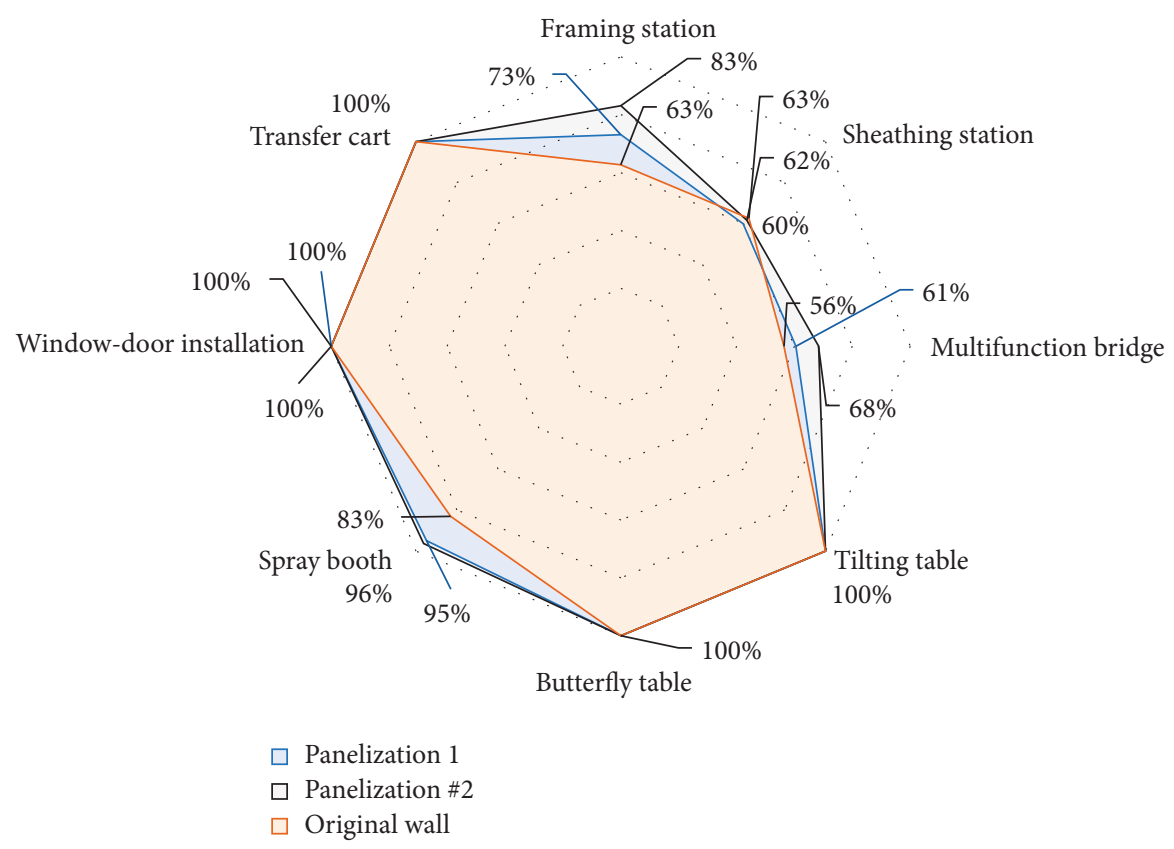

FIgURE 9: Workstation utilization.

by the prototyped system. The production durations and productivities are the mean value of all simulation runs. In this research, the number of simulation runs was set 200 times to increase the readability of simulation results because the simulation inputs involve probability distributions. As shown in the table, the production duration for alternative \# 1 is 290.08 mins, where there are 20 wall panels in total. On the contrary, the production duration for original walls without panelization is 321.16 mins. The results show that the production time is reduced by $9.6 \%$. In addition, Table 3 provides another panelization design alternative; for this example, the manufacturing time is about 307.82 mins when these exterior walls are manufactured into 27 wall panels. This design alternative could have $5 \%$ of time saving.
Notably, the panelization design with higher productivity can be generated by the prototype system; however, the resulting solution may not be the truly "global optimum." The reasons lie in the fact that this research employs a certain number of iterations in generating feasible solutions. Only a limited number of feasible solutions can be developed, and the best solution is chosen among these generated solutions.

6.2. Utilization and Total Duration of Each Workstation. Other statistics of the production performance can be used to provide insights into the various panelization designs. As described earlier, the developed simulation model can provide statistics such as utilization, cycle 


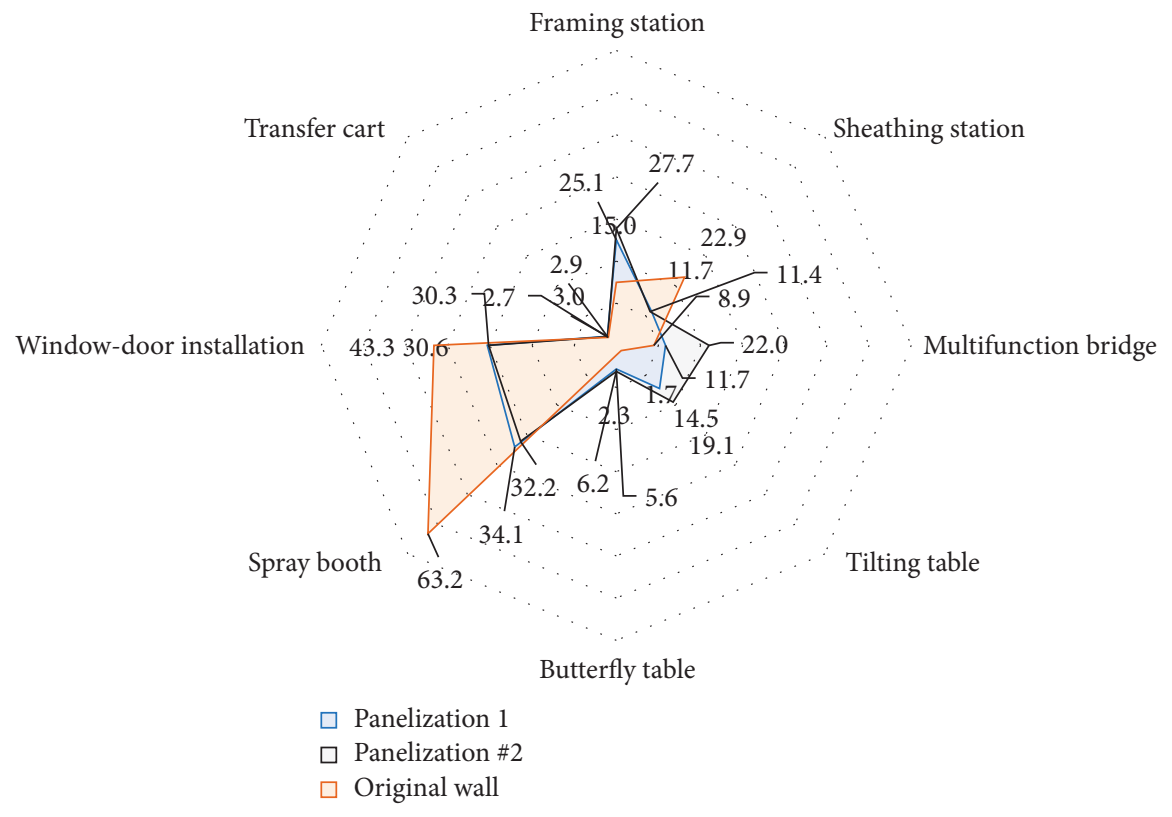

FIgURE 10: Total duration for each workstation, cycle time + waiting time.

time, and waiting time of each workstation. Figures 9 and 10 present the utilization and total duration of major workstations in the production line. Utilization herein is defined as the ratio of used capacity and the total capacity of workstations. The higher utilization indicates the higher level of working load and the criticality of the workstation. Increasing the capacity of workstations with high utilization may decrease the construction duration. As shown in Figure 9, the panelization design alternative \#1 increases the utilization for all workstations, which averages at $95 \%$. It might be due to the fact that wall panels are smaller than the original walls. When small wall panels are manufactured, a larger number of wall panels could be processed by the same workstation simultaneously, leading to the rise of utilization.

The total duration of workstations is the sum of waiting time and cycle time for which wall panels need to wait before entering workstations and stay in the workstation for completing the required operations. As shown in Figure 10, the total duration of each workstation for panelization design alternative \# 1 is generally shorter than other alternatives, implying a shorter manufacturing duration. The durations average at 22 mins. Original walls without panelization typically have a longer time for each workstation, as shown in Figure 10. For example, the duration of the spray booth can be as long as 63.2 mins. The simulation statistics, including cycle time, waiting time, and resource utilization from simulation results, were also confirmed by our industry partners, revealing that the simulation model mimicked the production processes in the field. These results, in turn, allow to verify and validate the developed simulation model.

\section{Conclusions and Future Work}

This research developed a BIM-based generative framework for panelization design. A prototype system was developed as an Autodesk Revit add-on to automate panelization design for improved manufacturing productivity. The prototyped system consists of three modules: (1) a BIM parser, (2) a rule-based panelization design algorithm, and (3) a simulation-based performance evaluation model. Panelization design rules are incorporated in the design algorithm to formulate feasible design alternatives. DES is employed to estimate the construction performance of each alternative for an optimized panelization design. An actual residential home was used as a case study to demonstrate the prototyped system. The results revealed that the developed system could generate and evaluate various design alternatives. Eventually, the system is proved to offer panelization design with improved productivity.

However, as mentioned earlier, the resulting panelization alternative might be a locally optimal solution. As such, optimization algorithms could be investigated for searching for a globally optimal solution. Also, the prototyped system can be further improved by incorporating timely data of the production line into the simulation model. For instance, the emerging Internet of Things (IoTs) technology can be applied to sense the production status continuously. It can be integrated with the proposed system to update simulation inputs for more realistic and accurate performance prediction. In addition, there are potential improvements using DfMA in a full project lifecycle to capture all project-related costs. The authors will explore the possibilities to develop a DfX framework for the OSC and to quantify the impacts of the design optimization on its project life cycle cost. The 
computational and generative design approach can be used to generate the design options that ultimately reduce construction waste and increase construction efficiency in the project life cycle.

The presented research contributes to the body of knowledge by the development of rule-based panelization algorithms and the BIM-DES based evaluation model that allow for the panelization design analysis and optimization for light-frame residential buildings. The resulting prototyped system automates building panelization by taking advantage of rich building information in BIM. The design automation takes a fashion of generative design, where the design algorithm generates a large number of feasible design alternatives, and the construction process simulation model predicts the construction performance in terms of manufacturing productivity. The proposed framework allows evaluating the manufacturing performance of building panelization during the design stage. In other words, it provides a quantitative method for practitioners to consider the DfMA principle at the design or preconstruction stage. Ultimately, the prototyped system allows for data-driven decision making for building panelization.

\section{Data Availability}

The data used to support the findings of this study are included within the article.

\section{Conflicts of Interest}

The authors declare that they have no conflicts of interest.

\section{Acknowledgments}

The authors gratefully acknowledge the assistance from ACQBUILT Inc., Edmonton, Canada.

\section{References}

[1] F. Barbosa, J. Woetzel, and J. Mischke, Reinventing Construction: A Route of Higher Productivity, McKinsey Global Institute, New York, NY, USA, 2017.

[2] A. Khalili and D. K. H. Chua, "IFC-based framework to move beyond individual building elements toward configuring a higher level of prefabrication," Journal of Computing in Civil Engineering, vol. 27, no. 3, pp. 243-253, 2013.

[3] J. P. Shewchuk and C. Guo, "Panel stacking, panel sequencing, and stack locating in residential construction: lean approach," Journal of Construction Engineering and Management, vol. 138, no. 9, pp. 1006-1016, 2012.

[4] Y. Lee, J. I. Kim, A. Khanzode, and M. Fischer, "Empirical study of identifying logistical problems in prefabricated interior wall panel construction," Journal of Management in Engineering, vol. 37, no. 3, Article ID 05021002, 2021.

[5] M. S. Altaf, A. Bouferguene, H. Liu, M. Al-Hussein, and $\mathrm{H}$. Yu, "Integrated production planning and control system for a panelized home prefabrication facility using simulation and RFID," Automation in Construction, vol. 85, pp. 369-383, 2018.

[6] C. Mao, F. Xie, L. Hou, P. Wu, J. Wang, and X. Wang, "Cost analysis for sustainable off-site construction based on a multiple-case study in China," Habitat International, vol. 57, pp. 215-222, 2016.

[7] S. Sharma, A. Sawhney, and M. Arif, "Parametric modelling for designing offsite construction," Procedia Eng.vol. 196, pp. 1114-1121, 2017.

[8] S. Martínez, A. Jardón, J. Gonzalez Víctores, and C. Balaguer, "Flexible field factory for construction industry," Assembly Automation, vol. 33, no. 2, p. 175, 2013.

[9] E. Alfieri, E. Seghezzi, M. Sauchelli, G. M. Di Giuda, and G. Masera, "A BIM-based approach for DfMA in building construction: framework and first results on an Italian case study," Architectural Engineering and Design Management, vol. 16, no. 4, pp. 247-269, 2020.

[10] S. Gao, S. P. Low, and K. Nair, "Design for manufacturing and assembly (DfMA): a preliminary study of factors influencing its adoption in Singapore," Architectural Engineering and Design Management, vol. 14, no. 6, pp. 440-456, 2018.

[11] Z. Yuan, C. Sun, and Y. Wang, "Design for Manufacture and Assembly-oriented parametric design of prefabricated buildings," Automation in Construction, vol. 88, pp. 13-22, 2018.

[12] S. Staub-French, E. A. Poirier, F. Calderon et al., Building Information Modeling (BIM) and Design for Manufacturing and Assembly (DfMA) for Mass Timber Construction, BIM TOPiCS Research Lab, University of British Columbia, Vancouver, Canada, 2018.

[13] A. Alwisy, S. Bu Hamdan, B. Barkokebas, A. Bouferguene, and M. Al-Hussein, "A BIM-based automation of design and drafting for manufacturing of wood panels for modular residential buildings," International Journal of Construction Management, vol. 19, no. 3, pp. 187-205, 2019.

[14] I. J. Ramaji and A. M. Memari, "Product architecture model for multistory modular buildings," Journal of Construction Engineering and Management, vol. 142, no. 10, Article ID 04016047, 2016.

[15] K. Chen and W. Lu, "Design for manufacture and assembly oriented design approach to a curtain wall system: a case study of a commercial building in Wuhan, China," Sustainability, vol. 10, no. 7, p. 2211, 2018.

[16] P. Jensen, T. Olofsson, and H. Johnsson, "Configuration through the parameterization of building components," Automation in Construction, vol. 23, pp. 1-8, 2012.

[17] P. Sharafi, B. Samali, H. Ronagh, and M. Ghodrat, "Automated spatial design of multi-story modular buildings using a unified matrix method," Automation in Construction, vol. 82, pp. 31-42, 2017.

[18] T. Salama, A. Salah, O. Moselhi, and M. Al-Hussein, "Near optimum selection of module configuration for efficient modular construction," Automation in Construction, vol. 83, pp. 316-329, 2017.

[19] S. Isaac, T. Bock, and Y. Stoliar, "A methodology for the optimal modularization of building design," Automation in Construction, vol. 65, pp. 116-124, 2016.

[20] S. Banihashemi, A. Tabadkani, and M. R. Hosseini, "Integration of parametric design into modular coordination: a construction waste reduction workflow," Automation in Construction, vol. 88, pp. 1-12, 2018.

[21] S. Banihashemi, A. Tabadkani, and M. R. Hosseini, "Modular coordination-based generative algorithm to optimize construction waste," Procedia Engineering, vol. 180, pp. 631-639, 2017.

[22] A.-Q. Gbadamosi, A.-M. Mahamadu, L. O. Oyedele et al., "Offsite construction: developing a BIM-Based optimizer for assembly," Journal of Cleaner Production, vol. 215, pp. 1180-1190, 2019. 
[23] H. M. Said, T. Chalasani, and S. Logan, "Exterior prefabricated panelized walls platform optimization," Automation in Construction, vol. 76, pp. 1-13, 2017.

[24] W. Lu, K. Chen, F. Xue, and W. Pan, "Searching for an optimal level of prefabrication in construction: an analytical framework," Journal of Cleaner Production, vol. 201, pp. 236-245, 2018.

[25] D. Lopez and T. M. Froese, "Analysis of costs and benefits of panelized and modular prefabricated homes," Procedia Engineering, vol. 145, pp. 1291-1297, 2016.

[26] Y. Chen, G. E. Okudan, and D. R. Riley, "Decision support for construction method selection in concrete buildings: prefabrication adoption and optimization," Automation in Construction, vol. 19, no. 6, pp. 665-675, 2010.

[27] M. Amer, A. Mustafa, and S. Attia, "Conceptual framework for off-site roof stacking construction," Journal of Building Engineering, vol. 26, Article ID 100873, 2019.

[28] H. Zaheraldeen, H. Khoury, and F. Hamzeh, An AHP Approach for Selecting and Identifying Offsite Construction Systems, Logistics and Supply Chain Management, Dublin, Ireland, 2019.

[29] S. AbouRizk and Y. Mohamed, "Simphony-an integrated environment for construction simulation," in Proceedings of the 2000 Winter Simulation Conference, vol. 2, pp. 1907-1914, Orlando, FL, USA, December 2000.

[30] H. Liu, Z. Lei, M. Lu, and M. Al-Hussein: Automated Production Planning in Panelized Construction Enabled by Integrating Discrete-Event Simulation and BIM Lean Innovation for Operations Management and Control in Manufacturing View Project Automation for Heavy Lift Study View Project," no. June, 2015, [Online]. Available: https:// www.researchgate.net/publication/279200553. 